УДК 349

\title{
ПРОБЛЕМЫ ПРАВОВОГО РЕГУЛИРОВАНИЯ ДЕЯТЕЛЬНОСТИ СОЦИАЛЬНЫХ СЕТЕЙ НА СОВРЕМЕННОМ ЭТАПЕ РАЗВИТИЯ ИНФОРМАЦИОННОГО ОБЩЕСТВА В РОССИИ
}

\begin{abstract}
Алиева Аида Рагимовна
студентка

Научный руководитель: Краснослободцев Кирилл Андреевич Старший преподаватель кафедры государственных и гражданскоправовых дисциплин Тамбовский филиал АНО ВО «Российский новый университет»
\end{abstract}

Аннотация: В статье исследуется феномен современной массовой коммуникации с точки зрения определения необходимых параметров правового регулирования информационного взаимодействия в формате социальных сетей. Проблемы соблюдения баланса частных и публичных интересов, защиты прав и свобод граждан, организаций рассмотрены в контексте правовой политики государства по урегулированию стандартов деятельности социальных сетей.

Ключевые слова: социальная сеть, информационная коммуникация, законотворчество, правовое регулирование, цифровая среда доверия.

\section{PROBLEMS OF LEGAL REGULATION OF SOCIAL NETWORKS AT THE PRESENT STAGE OF INFORMATION SOCIETY DEVELOPMENT IN RUSSIA}

\section{Aliyeva Aida Ragimovna Scientific advisor: Krasnoslobodtsev Kirill Andreyevich}

\begin{abstract}
The article examines the phenomenon of modern mass communication from the point of view of determining the necessary parameters of legal regulation of information interaction in the format of social networks. The problems of maintaining the balance of private and public interests, protecting the rights and freedoms of citizens and organizations are considered in the context of the state's legal policy on regulating the activity standards of social networks.

Key words: social network, information communication, lawmaking, legal regulation, digital environment of trust.
\end{abstract}


Феномен социальных сетей имеет достаточно сложную природу, которая не исчерпывается факторами развития современных средств коммуникации. Постановка проблемы изучения социальных сетей впервые была осуществлена в рамках социологии, когда вопрос об изучении модели поведения индивида стал рассматриваться не только в призме свойств самого индивида, но и с точки зрения воздействия социальной среды: структуры и характера социальных отношений внутри групп людей, объединенных различными интересами [1].

Социальное поведение индивида многогранно и информационное взаимодействие выполняет целый комплекс функций: общей коммуникации и социальной ориентации; поддержки обмена экономическими ресурсами; обеспечение политической и профессиональной, образовательной коммуникации. Социальное поведение в базовой части целеполагания и моделей удовлетворения потребностей по-своему остается неизменным, однако, социальная структура общества и механизмы социальной коммуникации на каждом этапе развития усложняются.

Индустриализация вместе с расширением слоя образованных людей в каждой страте общества привела к новому качеству социально-политического значения средств массовой информации, обусловила возникновение новых каналов связи в социуме по мере развития средств массовой информации в рамках научно-технической революции и начала радиовещания, телевещания.

Переход к информационному обществу демонстрирует нам следующий этап развития форм социальной коммуникации, когда технические возможности телекоммуникационной сети интернет открывают специфические форматы информационного обмена, характеризующиеся новыми качествами: возрастающей скоростью коммуникации, возможностью накопления большого массива данных в цифровой форме, экстерриториальностью коммуникации, деятельностью новых модераторов информации в лице агрегаторов информации.

Любое усложнение форм социальной коммуникации прямо коррелируется с возникновением новых рисков для устойчивого развития общества и государства. Интернет-коммуникация и современные социальные сети позволили обеспечить доступ широкому кругу физических и юридических лиц к созданию, транслированию, обработке и использованию большого массива данных, что позиционируется сторонниками цифровизации социальных процессов как существенное преимущество, создающее новое качество для рекламной, производственной образовательной деятельности. В то же время, массовая коммуникация обернулась целым рядом вызовов: 
необходимостью усиленного контроля за соблюдением режима конфиденциальности информации; возникновением большого количества ложной и недостоверной информации; развитием новых форм мошенничества и манипулирования сознанием широких масс людей.

В этом контексте справедлива постановка вопроса: в чем социальная ценность современных форм интернет-коммуникации и какой должна быть законодательная модель правового регулирования деятельности участников данного вида коммуникации?

Ценность интернет-коммуникации представляется в нескольких плоскостях. Очевидно, что интернет в лице сайтов, социальных сетей представляют собой эффективную систему передачи информации. Суть ценности с точки зрения распространения информации наилучшим образом иллюстрируется сравнительным обзором экспертных мнений в статье Алексея Сергеевича Воронкина «Социальные сети: эволюция, структура, анализ» [1], где наиболее интересна позиция Г. Рейнгольда: «Когда сеть похожа на телевизионную и вещает что-то людям, ценность ее услуг возрастает линейно. Когда же сеть дает возможность отдельным узлам вступать в контакт друг с другом, ценность возрастает в квадратичной зависимости. А когда та же самая сеть располагает средствами для создания ее участниками целых групп, ценность возрастает экспоненциально». То есть ценность раскрывается в категории возможности влияния на социальную самоорганизацию общества, побуждая людей к объединению на основе осмысления транслируемой информации.

Исходя из полноты осмысления ценности интернет-коммуникации, можно точно сформулировать критерии правового регулирования социальных сетей.

Главный критерий - информационное воздействие не должно влечь за собой нарушение прав и свобод, закрепленных в конституции, путем распространения противоправной информации. Такой подход был последовательно реализован законодателем в Федеральном законе от 27.07.2006 № 149-Ф3 «Об информации, информационных технологиях и о защите информации». В частности, ч. 1 ст. 10 указанного закона установлен принцип свободы распространения информации, но при обязательном соблюдении требований, установленных законодательством и в ч. 6 данной статьи мы находим указание на одно из главных требований: «Запрещается распространение информации, которая направлена на пропаганду войны, разжигание национальной, расовой или религиозной ненависти и вражды, а 
также иной информации, за распространение которой предусмотрена уголовная или административная ответственность».

Знаковым событием в правовой жизни России стала конкретизация признаков социальной сети и определение обязанностей владельцев социальных сетей в отечественном законодательстве в рамках разработки законопроекта № 223849-7 О внесении изменений в Федеральный закон «Об информации, информационных технологиях и о защите информации» и принятия соответствующего Федерального закона от 30.12.2020 № 530-Ф3 «О внесении изменений в Федеральный закон «Об информации, информационных технологиях и о защите информации».

Определение социальной сети получилось достаточно широким с точки зрения интерфейса, технологического взаимодействия с пользователями социальной сети: сайт (включая страницу сайта), информационная система, программа для электронных вычислительных машин. На наш взгляд, такой подход абсолютно оправдан, исключая формальное отрицание сущности социальной коммуникации на основании выбора той или иной технологии коммуникации. Важно подчеркнуть, что законодатель при этом вводит и дополнительные признаки социальных сетей: более 500 тыс. находящихся на территории России пользователей в сутки; распространение посредством созданных пользователями персональных страниц информации на государственном языке Российской Федерации, государственных языках республик в составе Российской Федерации или иных языках народов Российской Федерации, на которых может распространяться реклама, направленная на привлечение внимания потребителей, находящихся на территории Российской Федерации. Таким образом, в декабре 2020 г. был устранен пробел в российском законодательстве в части правового определения социальных сетей как явлений общественной и информационной жизни социума.

Важнейшей проблемой для правового регулирования деятельности социальных сетей является вопрос об обязанностях участников информационного обмена в рамках технологических особенностей формата социальных сетей. Российский законодатель в части обязанностей владельцев социальных сетей не только закрепил общий подход к запрету на размещение противоправной информации, обозначил необходимость соблюдения прав и законных интересов граждан и организаций (в том числе чести, достоинства и деловой репутации граждан, деловой репутации организаций), но и ввел требование мониторинга социальными сетями противоправного контента 
(детской порнографии, материалов связанных с незаконным оборотом наркотических средств, призывами к массовым беспорядкам, суицидам и др.). Вопрос мониторинга в модели правового регулирования, на наш взгляд, является одним из центральных в плане противодействия замены положительной модели информационного взаимодействия с целью образования, социального ориентирования на отрицательную, связанную с разрушением личности в частности и общества в целом. Справедлива ситуация, когда социальные сети, являясь главными бенефициарами массового потребления информации и извлечения прибыли из процессов, связанных с модерацией информации, будут содействовать государству в поддержании законного порядка в собственном информационном поле.

Главное в законотворческом процессе придерживаться принципов рациональности и эффективности правового регулирования. Так, спорным представляется предложение, выраженное в законопроекте № 145507-7 «О правовом регулировании деятельности социальных сетей и о внесении изменений в отдельные законодательные акты Российской Федерации», которое в пояснительной записке к указанному законопроекту сформулировано так: «В целях профилактики и борьбы с подобными явлениями (здесь авторы подразумевают пропаганду противоправного и асоциального поведения - A.P.) проектом федерального закона предлагается запретить пользование социальными сетями лицам, не достигшими 14-летнего возраста». На наш взгляд, стоит стремиться не к абсолютному запрету пользованию социальными сетями (особенно когда это связано с творчеством, образованием, обычной межличностной коммуникацией), а к созданию эффективных средств пресечения каналов передачи противоправной информации. Последнее может достигаться разными способами от государственного и корпоративного (со стороны социальной сети) мониторинга информации с целью выявления, удаления противоправного контента и привлечения к ответственности виновных лиц, до создания специализированных социальных сетей, ориентированных на определенные возрастные категории с дополнительными мерами технической модерации информации.

Сфера социального и информационного взаимодействия в рамках современных телекоммуникационных технологий требует особого регуляторного внимания от государства. Идеалом законотворчества условно можно назвать «цифровую среду доверия» в том смысле, что свободная коммуникация участников информационного обмена отвечает критериям безопасности, а общество и конкретные пользователи информационных систем 
доверяют действиям государства, нацеленным на поддержание безопасности [2]. В связи с этим мы считаем необходимым завершить нашу статью выводом, что по-настоящему (во всех смыслах: от предпринимательских задач, до творческих и образовательных) концепция социальных сетей станет успешной только при гарантии информационной безопасности, достижение которой лежит в плоскости конструктивного диалога между обществом и государством об оптимальных моделях правового регулирования информационного взаимодействия в сети интернет с учетом современных социальноэкономических потребностей и необходимостью охраны общественной морали, нравственности, ценностей традиционной культуры народов России.

\section{Список литературы}

1. Воронкин Алексей Сергеевич Социальные сети: эволюция, структура, анализ // ОTO. 2014. №1. URL: https://cyberleninka.ru/article/n/sotsialnye-setievolyutsiya-struktura-analiz.

2. Кузнецов Владимир Иванович, Кабытов Павел Петрович. Теоретические подходы к категории «цифровая среда доверия» // Юридические исследования. 2021. №2. URL: https://cyberleninka.ru/article/n/teoreticheskiepodhody-k-kategorii-tsifrovaya-sreda-doveriya.

(C) А.Р. Алиева, 2021 